\title{
Tratamiento contra la rabia humana: un poco de su historia
}

\section{A historical review of the treatment of human rabies}

\author{
Maria Cristina Schneider*, Carlos Santos-Burgoa**
}

SCHNEIDER, M.C. \& SANTOS-BURGOA, C. Tratamiento contra la rabia humana: un poco de su historia. Rev. Saúde Pública, 28: 454-63, 1994. El presente trabajo es una revisión histórica del tratamiento utilizado contra la rabia humana, desde la antigüedad hasta el momento actual. Pretende hacer una analogía entre el concepto de causa predominante en la época y el tipo de tratamiento utilizado. Los griegos antiguos tenían la diosa Artemisa como sanadora de la rabia y ya utilizaban la cauterización de la herida. Los pueblos del siglo I conocían la capacidad infecciosa en la saliva de perros rabiosos, llamando a ese material de veneno virus (en latín). En la Edad Media, cuando prevalecía un concepto mágico y religioso de la salud, el gran protector era San Humberto. Con el Renacimiento surgen nuevamente muchos experimentos y avances en el conocimiento de la enfermedad, que sentaron las bases para los importantes hallazgos en el futuro próximo. En esa época predominaba la teoría miasmática y del contagio. Pasteur fue un grande opositor de la espontaneidad de la rabia. A finales del siglo XIX, con los descubrimientos microbianos, Pasteur hizo la gran revolución científica en relación al tratamiento contra la rabia, que es la vacuna. Las vacunas pueden actualmente ser de tipo nervioso o no, variando también el numero de dosis recomendadas. Se han desarrollado muchos estudios sobre vacunas, siendo la más utilizada en América Latina del tipo Fuenzalida y Palacios, y la recomendada actualmente por la OMS es la de cultivo celular.

Descriptores: Rabia, prevención \& controle. Vacuna antirrabica.

\section{Introducción}

La rabia es una enfermedad conocida y discutida desde la antigüedad. En las cartas de Vital ${ }^{42}$ es citada como una enfermedad de los mamíferos carnívoros, que apareció al mismo tiempo que los animales. Tal vez por su cuadro clínico tan impresionante, esta enfermedad ha sido ampliamente descrita, tanto por los grandes historiadores de la antigüedad, como por la literatura médica en las distintas épocas.

Las personas siempre han buscado formas de evitar las enfermedades y estas formas son determinadas por la manera que ellas comprenden la causa de la enfermedad. El determinismo causal $^{7}$ y los hechos científicos que ocurren están adheridos, en un momento dado, a una sociedad

\footnotetext{
* "Centro Nacional de Epidemiologia. Fundação Nacional de Saúde". Ministério da Saúde - Brasil. Aluna del doctorado en ciencias de la Escuela de Salud Publica de México. Instituto Nacional de Salud Publica Cuernavaca - México

* Escuela de Salud Publica de México. Instituto Nacional de Salud Publica - Cuernavaca- México

Separatas/Reprints: M.C.Schneider - 14306 Night Hawk Way
} North Potomac, MD 20878 - USA históricamente definida y de acuerdo, en la mayoría de la veces, con el pensamiento hegemónico de la época. Pero la ciencia no es estática, siempre se están rompiendo los paradigmas y creando nuevos, de esta forma aceptamos como ciencia en la antigüedad, lo que para nosotros hoy son mitos y supersticiones. Según Kuhn ${ }^{18}$, las teorías antiguas no dejan de ser científicas por el hecho de que hayan sido descartadas.

El objetivo de este ensayo es hacer una revisión histórica sobre el tratamiento contra la rabia humana empezando por ver cómo las personas observarón la rabia como enfermedad, qué causas establecieron y cómo la tratarón hasta el renacimiento. En un segundo momento, se pretende discutir la revolución científica en relación al tratamiento humano contra la rabia, que ocurrió con el descubrimiento de la vacuna de Pasteur, hecho que se mantiene hasta hoy, finalmente describir los tipos existentes de vacunas contra la rabia.

Creemos interesante hacer una analogía del concepto de causa del proceso salud/enfermedad que predominaba en la época, con el tipo de tratamiento que era conocido para evitar la rabia; hasta llegar a los días de hoy, en los cuales la vacunación de animales y el tratamiento de personas agredidas han sido las principales acciones 
utilizadas para lograr el control de la rabia en varios países.

\section{El tratamiento contra la rabia em los pueblos antiguos hasta el renacimiento.}

En la antigüedad habián dos interpretaciones sobre las causas de las enfermedades. Una manera vista por los asirios, egipcios, caldeos, hebreos y otros pueblos, que era de carácter religioso, y la otra desarrollada por los chinos e indues, en que la enfermedad era vista como un desequilibrio entre los elementos que componían los organismos humanos 4 .

En la mitología griega Homero se refiere a la rabia en la Ilíada cuando menciona que "Sirius", la constelación perro de Orión, ejerce una influencia maligna sobre la humanidad. La estrella perro Sirio se asociaba con perros rabiosos, a través del Mediterráneo Oriental, Egipto y Roma'. También escribe Homero que el invencible Héctor era un perro rabioso ${ }^{29}$.

Para los griegos en esta época, la diosa Artemisa era la sanadora de la rabia y el dios Artiste, hijo de Apolo, era especial para combatir el efecto de la rabia ${ }^{39}$.

Hipócrates también escribió sobre la rabia describiendo su sintomatología ${ }^{42}$. Él recomendaba como prevención para la rabia la madera de boj (Buxus) ${ }^{1}$. Hipócrates desarrolló en su libro "Aires, Aguas y Lugares" la influencia del medio ambiente en la enfermedad. Los griegos concebían los problemas del salud como una interrelación entre el hombre y la naturaleza ${ }^{31}$.

La primera descripción registrada de la rabia la hizo Democrito en 500 A.C. ${ }^{39}$ Aristóteles ${ }^{42}$, Luciano ${ }^{1}$ y otros hablaron de la propagación de la rabia a través de la mordedura de perros.

Ya en la Grecia antigua era reconocida la cauterización de las heridas causadas por animales rabiosos ${ }^{42}$; este tratamiento se mantuvo hasta el descubrimiento de las vacunas.

Los romanos recibierón como legado de los griegos muchas ideas sobre salud y medicina y desarrollarón muy bien los aspectos sanitarios ${ }^{31}$. Ellos describían la capacidad infecciosa en la saliva de los perros rabiosos, llamando a este material infeccioso veneno que proviene de la palabra latina virus, del siglo $\mathrm{I}^{1}$.

La rabia ha sido una de las enfermedades cuya descripción de la historia natural se mantiene de la misma manera hasta hoy. El "concepto" de transmisibilidad, identificado desde un inicio a través de la saliva de los perros, y la utilización de la palabra virus para definir el material infeccioso, son paradigmas aceptados hasta nuestros días.
Otra causa de la rabia descrita en la antigüedad por Plinio y Ovidio es la llamada gusano de la lengua del perro. En aquellos tiempos se cortaba el freno de la lengua del perro y se extirpaba un pliegue en el cual pudiera estar el gusano, esta teoría permaneció hasta Pasteur.

El tratamiento preventivo romano en el siglo I, recomendado en el libro de Celsus ${ }^{42}$ era: Aplicación de ventosas para extraer el veneno (virus); cauterización por hierro caliente 0 sustancias cáusticas; baño con sudación; beber vino, por considerarlo un antídoto contra varios venenos.

Varios tratamientos eran recomendados en esa época como nieve, pajilla en cuarto oscuro, enemas, escarificaciones, sangrías y otros ${ }^{1,42}$. Algunos de estos tratamientos como la cauterización, tenían un sustento empírico, porque estarían evitando la penetración del virus en el organismo.

Otro grupo de pueblos antiguos también citaban a la rabia, como los egipcios que la atribuían a la penetración de un demonio en el cuerpo y se invocaba a San Taraba para expulsarlo. La rabia es citada en la Biblia ${ }^{42}$. En China (472-221-A.C.) era utilizada maxibustán, que es el equivalente de la cauterización $\mathrm{n}^{42}$. La Sucrutasamitá (siglo I) es el primer texto médico sobre la rabia en la India ${ }^{42}$.

Hay muchos relatos en este periodo de la historia sobre la rabia que demuestran que era una enfermedad bastante estudiada, probablemente por ser un problema importante en todo el imperio romano, en particular, en la Grecia. Pero hasta la Edad Media las epizootias eran raras, los casos de rabia a pesar de frecuentes, eran aislados.

Con el crecimiento poblacional de las ciudades medievales y con los problemas sanitarios de éstas surgieron varias epidemias, como la de peste. Entre las enfermedades presentes en las comunidades medievales estaban la lepra, varicela, difteria, tuberculosis, sarampión y otras $^{31}$. La rabia también marcaba su presencia con invasiones de animales rabiosos en los pueblos y villas ${ }^{1}$.

En la Edad Media, a pesar de seguir los principios hipocráticos, los problemas de salud eran considerados como causas mágicas y religiosos, y se mezclaba la influencia pagana de los bárbaros con la religión cristiana hegemónica. El cristianismo colocaba una conexión fundamental entre la enfermedad y el pecado. Consecuentemente, la forma de tratarla era por medio oraciones, penitencias e invocación de santos ${ }^{31}$.

En este periodo el gran protector de la rabia 
ha sido San Humberto. El hecho de que San Humberto curara la rabia ha sido una discusión entre las instituciones científicas de la época, como la Sorbone y la Iglesia Católica. Con base en la protección de San Humberto, se utilizaba la aplicación de un hierro caliente en los perros mordidos por otros rabiosos, que se llamaban las llaves de San Humberto. Como amuleto se utilizaba un anillo de hierro insertado en la pared de una de las casas principales ${ }^{39}$. Los sacerdotes desprendían una partícula de hilo de la estola de San Humberto y la introducían bajo la piel de la frente de la persona mordida. Las peregrinaciones a San Humberto, en Bélgica, también eran muy utilizadas ${ }^{29}$. Hasta el siglo IX la creencia en este santo era muy grande entre los campesinos.

En la Edad Media se seguía la terapéutica de cauterizar las heridas, juntamente con otras medidas, como por ejemplo la aplicación de cataplasmas a bases de extractos vegetales ${ }^{42}$.

Barata ${ }^{4}$ relata que ya existía el concepto del contagio en el siglo XIV, pero como se mencionó anteriormente, la idea de transmisión en la rabia data del siglo I, en la antiguiedad.

El primer gran brote de rabia descrita fue en Francia en 1271, cuando una villa fue atacada por lobos rabiosos. En 1500, España estaba asolada por rabia canina, la ciudad de Paris en 1614 y así, casi toda la Europa central. Con el surgimiento del brote de rabia canina en la ciudad de Londres de 1752-1762, fue ordenado el sacrificio de todos los perros callejeros, que incluyó la paga de una recompensa por animal muerto, originando una masacre de estos animales. Esta práctica fue utilizada en localidades como Madrid, donde matarón 900 perros en un solo día; en Inglaterra, en 1779 , no era permitido a los pobres que tuvieran perros ${ }^{39}$.

Durante el Renacimiento la medicina vuelve a ser ejercida predominantemente por legos; los experimentos y las observaciones anatómicas fuerón retomados, dando por resultado la formación de las ciencias básicas.

Para intentar explicar el gran número de epidemias que asolaban Europa al final de la Edad Media, se concibió la teoría miasmática, a la mitad del siglo XVII. Esta teoría elaborada por Sydeham y otros, está basada en que la enfermedad se origina por la emanación sucia del suelo y aguas impuras ${ }^{4}$.

La teoría miasmática podría explicar cómo la rabia surgió por primera vez en aquella localidad, sin embargo siempre permaneció el concepto de transmisión a través de un animal enfermo. Dentro de esta teoría, la causa de la rabia es citada por medio de la absorción de sustancias en descomposición o por la con- versión de humores melancólicos ${ }^{42}$.

Para la salud pública, con el Renacimiento empieza un nuevo período en la historia, el moderno, donde las civilizaciones medievales desaparecen y nace el Nuevo Mundo, y en éste las raíces de las ciencias modernas ${ }^{31}$. Con relación a la rabia, también hubieron muchos experimentos y avances en el conocimiento de la enfermedad ${ }^{39}$. Con el desarrollo de la clínica, surgierón nuevas propuestas en cuanto al tratamiento de la rabia, la mayoría incluyó la limpieza de la herida y algún procedimiento en el lugar de la mordedura, como la aplicación de hierro caliente o productos químicos, tales como el mercurio. Para la ciencia de nuestro días, ambos procedimientos tienen sentido, pueden no estar totalmente correctos, pero la limpieza de la herida y la aplicación de un producto para impedir la entrada e instalación del virus son conocidos.

En esta época la rabia era muy común por toda Europa hasta la Ucrania, ocurriendo brotes importantes en varios países. No fue sino hasta el inicio del siglo XIX cuando la rabia canina pasó a las Américas causando brotes en varios países ${ }^{1}$.

En Estados Unidos de Norteamérica la rabia se tornó un problema muy serio entre los perros y animales silvestres, utilizando "las piedras de la rabia" ("piedras lunares"). Estas piedras eran cálculos biliares de animales que eran hervidas en leche y colocadas en la herida!

Según Radot $^{29}$, en un pequeño manual del siglo XVII titulado "Los remedios caritativos de la Señora Fouquet" se encuentra la siguiente receta: Un buen remedio para las mordidas en cualquier parte del cuerpo por perros, gatos, lobos u otros animales rabiosos son los baños de mar en el Mediterráneo o en el Océano, tomados oportunamente, esto es, antes de que el veneno haya alcanzado partes hábiles del organismo, fenómeno que ordinariamente sucede dentro de los 9 días.

En esta época se aconsejaba la playa Dieppe para las personas amenazadas de rabia, tanto que dio origen a una comedia "La rabia de amor", que sucedía en la playa de Dieppe, representada en París en $1725^{29}$.

La cauterización que es conocida como tratamiento desde la antigüedad siguió siendo recomendada por varios médicos franceses durante el Renacimiento. Bouchandt de la facultad de León, hizo varias propuestas terapéuticas y fue el primero en pensar en la posibilidad de inoculación contra la rabia, influenciando a Pasteur $^{39}$. En la época de los experimentos de Bouchandt la escuela de veterinaria de León, notificaba el mayor número de perros rabiosos 
que se había presentado. Esto recuerda que la ciencia sufre grandes influencias por las necesidades de respuestas a sus problemas en aquel momento.

En este período era muy común matar a los enfermos o sospechosos de rabia, llegando al punto de ser propuesto en Francia en 1810, una ley concebida en estos términos: "Bajo pena de muerte, prohibese estrangular, asfixiar, desangrar por las cuatro extremidades o matar de cualquier otra manera a las personas atacadas de rabia, hidrofobia o cualquier otra enfermedad que provoque accesos, convulsiones o locura furiosa. Correspondiente a la policía y a la familia de las victimas, tomar precauciones para proteger la salud pública y la particular"29.

Segundo Rosen ${ }^{31}$ en el siglo XIX, se podían distinguidas tres posiciones teóricas con relacion del origen de las enfermedades:

- La miasmática, en la cual los brotes epidémicos de las enfermedades infecciosas eran causadas por el estado de la atmósfera. Esta teoría dio origen a muchas de las reformas sanitarias propuestas por Chadwick y Smith.

- La del contagio, propuesta por Show y Budd, en la cual defendía que los contagios específicos eran las causas de las infecciones y epidemias.

- La que intentaba conciliar la teoría miasmática y de contagio, que puede ser llamada de contagionismo contigente, propuesta por Simón y van Pettenrofer.

La rabia también era discutida a partir de estas distintas teorías, existiendo trabajos que refirien la existencia de dos formas de rabia, la espontánea y la transmitida. Podían creer en la espontaneidad de la rabia a través de la teoría miasmática, pero nunca negaban su transmisión. Pasteur fue uno de los grandes opositores de la espontaneidad de la rabia, como se describe a continuación.

\section{La gran revolución científica en el tratamiento contra la rabia: la vacuna de Pasteur}

Con el descubrimiento microbiano ocurrido en la mitad del siglo XIX, fue posible dar el gran brinco en el tratamiento contra la rabia. La forma eficaz de impedir que las personas murieran de rabia empezó con la vacuna de Pasteur, logrando la tan esperada posibilidad de tratar a las personas agredidas por animales supuestamente rabiosos, que era uno de los importantes problemas de salud pública de la época.

La bacteriología afectó profundamente a la salud pública, a través del desarrollo de la aplicación de la inmunología. La primera vacuna descubierta fue la de viruela en 1798 por Jenner, antes mismo de la era bacteriológica. En esta época, fueron desarrollados muchos estudios sobre microorganismos, su transmisión y tratamientos. Fue demostrada también la transmisión a través de vectores, como el caso del mosquito y la malaria. Koch ha sido el otro gran protagonista de la era bacteriológica, juntamente con Pasteur.

Algunos estudios como los de Zinke (1804), que demostró por primera vez que la rabia podía ser transmitida a conejos y perros infectando heridas cutáneas con saliva, contribuyeron bastante para los descubrimientos de Pasteur ${ }^{1}$. Antes de demostrar la posibilidad de inmunizar contra la rabia, Pasteur estableció los principios de la inoculación profiláctica en 1881 contra anthrax y en 1883 contra erisipela porcina ${ }^{31}$.

En esta época muchos creían en la espontaneidad de las enfermedades, inclusive de la rabia. Como ya se mencionó anteriormente, Pasteur se postuló contra esta teoría, como podemos ver a través de una de sus cartas sobre la rabia:

Hasta hace poco, nuestros conocimientos sobre la rabia estaban mezclados por una cantidad de prejuicios. Se creía por ejemplo, que la rabia podía nacer espontáneamente e incluso se describian las causas ocasionales del mal. En las calles de ciertas ciudades, a menudo se colocaba a lo largo de los muros en verano, pequeños vasos de estaño llevando agua, para que los perros pudieran satisfacer su sed. Huchas personas pensaban que si se descuidaban estas precauciones, los animales estaban expuestos a contraer la rabia. No obstante, es un hecho que bajo cualquier condición fisiológica o patológica en que se coloque a un perro o cualquier otro animal, jamás se manifestará la rabia en este animal síno ha sido mordido o lamido por algún otro que tenga la rabia en el momento que se ha producido la herida; pero es preciso, dirán, que ¿ haya habido un primer animal con rabia? Esta es una demanda que abre simplemente la cuestión del origen de todos los casos, cuestión absolutamente fuera del dominio de las investigaciones científicas. ¿De dónde viene el primer hombre? ¿de dónde salió el primer roble? Nadie lo sabe y es inútil discutir sobre misterios parecidos (Pasteur) ${ }^{28}$.

Cuando Pateur empezó sus estudios ya se conocía bastante sobre la enfermedad, específicamente la transmisión a través de mordeduras de animales y la presencia de un virus en la saliva; además, el cuadro clínico estaba bien descrito y 
también el período de incubación de la rabia.

El experimento de Pasteur empezó por la inoculación de la saliva de un niño enfemo en conejo sin mucho éxito, pero siguió igual con sus estudios ${ }^{29}$.

El primer informe sobre la rabia a la academia científica data del año de 1881 y hablaba sobre la dificultad encontrada en las investigaciones debido al largo tiempo de los períodos de incubación de la enfermedad, resuelto más tarde por él mismo, con trepanaciones para inocular perros y conejos directamente en el cerebro ${ }^{28}$.

Pasteur probó que el virus de la rabia se encuentra en mayor cantidad en el cerebro, pudiendo de esta forma tener éxito en sus inoculaciones. Logró atenuar el virus a través de varios pases.

Hizo estudios experimentales al provocar la agresión de perros rabiosos a otros perros y vacunar unos y otros no, encontrando que los vacunados no morían. La comisión fiscalizadora de la rabia, recomendó la construcción de una gran perrera, para que pudiera mejor desarrollar sus estudios ${ }^{29}$.

En 1885, Pasteur por primera vez trató con éxito a un niño (Joseph Meister) muy agredido por un perro rabioso ${ }^{28}$. Éste fue un gran paso en la ciencia, lograr tratar una enfermedad letal y altamente frecuente en esa época, como la rabia.

La comunicación de Pasteur a la Academia de Ciencias, ya después de tener la seguridad de sus resultados sobre el tratamiento de Joseph Meister, data de 26 de octubre de 1885 , con la siguiente cita:

Joseph Meister ha escapado, por tanto, no sólo a la rabia que las mordeduras habrian podido desarrollar, sino a aquella que le inoculé para control de la inmunidad debido al tratamiento, rabia más violenta que aquella que producen los perros callejeros. (Pasteur) ${ }^{28}$.

Desde el primer tratamiento en enero de 1885 , hasta octubre de 1886 , Pasteur ya había tratado 2.490 personas, siendo 1.726 provenientes de Francia y Argelia y las demás de distintos países, inclusive de Rusia y Estados Unidos ${ }^{28}$.

El tratamiento de Pasteur tenía una mortalidad del 1 al $2 \%$, cuando era iniciado a tiempo ${ }^{42}$. Esta mortalidad es bastante baja, recordando que existen personas con deficiencia inmunológica que pueden no responder al tratamiento, además de ser en aquel momento una vacuna recién desarrollada.

Empezó a recibir donaciones de varias partes del mundo, con las cuales fue posible empezar la creación del Instituto Pasteur. Diez años después el Instituto tenía centros de investigación de varios países

Sin duda Pasteur fué el científico que hizo una revolución en la forma de tratar la rabia. El tipo de vacuna y el número de dosis ha evolucionado mucho, pero el tratamiento preventivo antirrábico a personas agredidas por animales sigue teniendo las mismas bases.

\section{De Pasteur hasta hoy}

La vacuna utilizada por Pasteur era de tejido nervioso con virus vivo, fijado a través de varios pasajes en conejos ${ }^{43}$. Pequeñas modificaciones fueran hechas, como por Roux (1887) y Calmette (1891), cuando introdujeron el uso de la glicerina para la conservación de las médulas, permitiendo el envío de vacunas para áreas distantes ${ }^{9}$. Por el miedo de provocar la enfermedad en personas vacunadas, pasaron a inactivarla a través de los estudios de Fermi (1908) y después Semple (1919).

Podemos clasificar las vacunas existentes actualmente en dos grandes grupos, las de tejido nervioso y las de tejido no nervioso.

\section{Las vacunas de tejido nervioso}

Las vacunas de tejido nervioso adulto tipo Fermi o Semple han sido utilizadas hasta los años 50. Se usó mucho la vacuna Semple en Estados Unidos para tratar a personas, hasta la comercialización de la vacuna de embrión de pato (DEV), en $1957^{38}$.

Un triste episodio de la historia de las vacunas de tipo Fermi, ocurrió en Brasil en 1960, cuando todavía no existía el Programa de Rabia. El cambio involuntario de las muestras de virus para la fabricación de la vacuna, ocasiono de encefalitis rábica en $27,3 \%$ de las personas vacunadas, llevando a la muerte a 18 personas en Fortaleza/CE ${ }^{27}$.

Otro estudio histórico sobre la prevención de la rabia humana utilizando la vacuna Semple y suero, fue hecho por Baltazar et al. ${ }^{3}$ en Irán, analizando la respuesta del tratamiento en personas agredidos por lobos. El porcentaje de muerte por rabia en personas tratadas fue de $18,5 \%$. Si recordamos los porcentajes logrados por Pasteur en sus primeros tratamientos que eran entre 1 y $2 \%$, ya citado anteriormente, nos sugiere que había algún problema con la vacunación en Irán en aquel momento.

Con el desarrollo de la vacuna tipo Fuenzalida y Palacios, en 1954, hecha de cerebro de ratón lactante (CRL) que no debería contener mielina, bajó mucho los accidentes. Esta vacuna 
es la más utilizada en Latinoamérica, tanto para inmunizar humanos como perros. Solamente Brasil produce y distribuye 2 millones $500 \mathrm{mil}$ dosis humanas y 18 millones de dosis caninas. La proporción de accidentes neurológicos, postvacunales en personas tratadas con este tipo de vacuna en Brasil, está en 1:35.000 esperado según Turner ${ }^{44}$, que es de 1:8.000 tratados.

Segundo $\mathrm{Baer}^{2}$, dice: la vacuna $C R L$ no es costosa y en muchos países se le considera como un producto bastante potente y barato.

La disponibilidad de vacunas antirrábicas de alto poder antigénico, como las de cerebro de ratón lactante (SMB) o células diploides humanas ha permitido disminuir el número de dosis usadas en el tratamiento de personas expuestas. El número de dosis recomendadas para la vacuna CRL varían entre $13(10+3$ refuerzos) y 16 (14 +2 refuerzos), según Díaz et at. ${ }^{1}$. La última Norma Técnica de Brasil ${ }^{13}$ recomendó como tratamiento profiláctico mínimo $9(7+2$ refuerzos) dosis.

\section{Las vacunas de tejidos no nervioso}

Las más recientes fueron desarrolladas con el intento de no tener sustratos de tejido nervioso, objetando la no ocurrencia de accidentes post-vacunales.

Los primeros estudios en relación a adoptar el crecimiento de virus fijo en embrión de pollo fueron desarrollados por Koprowski y $\mathrm{Cox}^{17}$ en 1948. Ellos crearon las vacunas tipo Flury LEP y Flury HEP en embrión de pollo, que son vacunas de virus vivo atenuado utilizadas para perro y ganado, respectivamente ${ }^{43}$. La vacuna LEP ha sido utilizada en varios países por ejemplo en Estados Unidos e Israel entre los años 1953 y 1968, la vacuna HEP es todavía utilizada, pero no es muy segura para cachorros, gatos y ganado. Ambas vacunas son todavía producidas para ser utilizadas en animales silvestres con algunas modificaciones ${ }^{10}$. Estas vacunas fueron usadas de forma comercial sólo para uso animal, probablemente por ser virus atenuado. Sin embargo, han sido realizados estudios experimentales en personas, como el de Ruegsegger et al. ${ }^{32}$ y Sharpless et al. ${ }^{36}$ en la tentativa de pasar a utilizar la vacuna Flury en humanos.

La vacuna inactivada para uso humano hecha en embrión de pato fué desarrollada por Powell et al ${ }^{43}$, en 1950 . Este tipo de vacuna produce muy poca actividad encefalitogénica, pero el elevado contenido de tejido embrionario conduce con frecuencia a reacciones alérgicas menores a los diversos antígenos. Estudios llevados a cabo en dónde se compara la vacuna de embrión de pato (DEV) conotras vacunas han sido reportados por Greenberg et al. ${ }^{14} \mathrm{con}$ la tipo Semple y por Sikes e col. ${ }^{37}$ que compara las dos anteriores más la de cerebro de ratón. También han sido estudiadas modificaciones en la metodología a través de la purificación por ultracentrifugación ${ }^{24}$.

Según Clark et al. ${ }^{9}$, el método de la vacunación original de Pasteur fue empleado por última vez en el Instituto de Pasteur de Francia en 1953, esto quiere decir que siguió siendo utilizada durante 68 años. El mismo autor sugiere que las vacunas contra la rabia tardaron tanto en presentar mejoras significativas debido a dos factores: la imposibilidad de hacer estudios experimentales de nuevos tipos de vacuna en el hombre después de una exposición; y el otro, por la profunda y tradicional aceptación de los venerables métodos de tratamiento, fundados en los descubrimientos de Pasteur y sus contemporáneos. Creemos que el paradigma creado por Pasteur ha sido tan fuerte que hasta hoy persiste.

Las vacunas de cultivo celular empezaran en los años 60, primeramente en nivel experimental con los estudios de Kissling et al ${ }^{43}$

Las vacunas de cultivo celular de célula diploide humana (HDCV), descrita por la primera vez por Wiktor, han sido muy utilizadas para la profilaxis humana post-exposición a partir de los años 70. Segundo $\mathrm{Baer}^{2}$ menciona que la vacuna es sumamente potente y aun después de la administración de millones de dosis de vacuna, las reacciones adversas han sido sumamente raras. El número de dosis recomendado por la $\mathrm{OMS}^{25}$, es de 5 dosis para post-exposición.

Las vacunas de cultivo celular son consideradas por muchos como un salto en la calidad de tratamiento contra la rabia, disminuyendo los riesgos de accidentes post-vacunales y bajando el número de dosis.

El último Informe del Comité de Expertos de la OMS en rabia ${ }^{47}$ recomienda el uso de vacunas de cultivo celular. El esquema propuesto de aplicación es una dosis de vacuna administrada en los días $0,3,7,14$ y $30^{47}$. En este informe también no recomiendan más el uso de vacunas de tejido cerebral, que es la utilizada en la mayor parte de los países de Latinoamérica.

Los méritos de esta vacuna de cultivo celular son importantes, pero tienen un inconveniente muy grande que es el costo. Esta vacuna puede llegar a costar US\$ 80 la dosis, con un costo de US\$ 400 para un tratamiento completo ${ }^{2}$. Para Brasil el costo se estima en aproximadamente 20 veces más que la del cerebro de ratón lactante que viene siendo utilizada. Para los países de Latinoamérica, como por ejemplo Brasil dónde se trata gratuitamente a 
180.000 personas por año agredidas por animales, en dónde se produce la cantidad de vacuna necesaria, de buena calidad, a costos muy bajos, creemos que no se justifica la importación de vacunas de cultivo celular de países más desarrollados. Más bien, es conveniente utilizar estos recursos en el desarrollo de tecnología nacional para producir vacunas más actualizadas, así como para reforzar las acciones recomendadas para el control de la rabia.

Las vacunas de cultivo celular han sido bastante estudiadas ${ }^{30,45}$, demostrando buenos resultados en la seroneutralización de las personas vacunadas. Ha sido también discutido la ocurrencia de hipersensibilitad en la aplicación de refuerzos con este tipo de vacunas ${ }^{23}$.

Otros tipos de vacuna de cultivo celular están siendo desarrollados, principalmente con el objetivo de bajar los costos. La vacuna purificada de células VERO es aproximadamente la mitad del precio de la diploide humana ${ }^{15}$. Varios estudios fueron hechos comparando estos dos tipos de vacunas ${ }^{15,40}$. Otros tipos de células también están siendo utilizados con las de mono Rhesus ${ }^{5}$, de embrión de pollo purificado ${ }^{3.3}$ y otras.

Recordemos que el tratamiento contra la rabia es siempre preventivo, esto es, impedir que la enfermedad se desarrolle en el organismo; una vez que empiezan los primeros síntomas prácticamente es irreversible la muerte. Existen dos tipos de tratamiento el de pre-exposición recomendado a personas muy expuestas al riesgo de contraer rabia y el de post-exposición que es recomendado para las personas agredidas por animales.

Los primeros estudios con la utilización de inmunización pasiva contra la rabia datan de 1890 (Babes y Lepp). De esta fecha hasta Koprowski et al. ${ }^{16}$, los estudios eran experimentales principalmente en animales y algunos pocos en hombre, como los de Shortt (1935) y Proca $(1937)^{x}$.

Las investigaciones sobre el efecto del suero en el tratamiento antirrábico humano, tuvieron mayor repercusión con los estudios de Koprowski et al. ${ }^{16}$, dando origen a una serie de estudios bajo los auspicios del Comité de Expertos sobre Rabia de la Organización Mundial de la Salud. Uno de los más conocidos ha sido en Irán, cuando un lobo rabioso entró en una aldea y mordió a 29 personas. Se aplicó suero a las víctimas y se logró una disminución considerable en el porcentaje de mortalidad en las personas tratadas ${ }^{8}$.

La importancia mayor en la aplicación de suero se da en los casos graves (mordeduras múltiples, profundas o en cabeza y manos), cuando el período de incubación puede ser muy corto; de esta forma, la inmunoglobulina actuaría antes de la vacuna para presentar títulos protectores.

La aplicación del suero conjuntamente con la vacuna para el tratamiento preventivo contra la rabia empezó a ser recomendado por el Comité de Expertos de la OMS a partir de 1973 y sigue siendo recomendado hasta hoy ${ }^{25}$. Estudios como el de Kuwert et al. ${ }^{19}$, en dónde so combinó la inmunoglobulina humana con vacuna de células diploides humanas, demostró que no hay diferencia significativa entre el nivel de anticuerpos, utilizando sólo vacuna o las dos. Esta cuestión ya había sido investigada con la administración conjunta de sueros y otros tipos de vacuna, en la cual era recomendada la aplicación de refuerzo para compensar la interferencia que ocurría con la aplicación de ambas".

Actualmente existen dos tipos de inmunoglobulina contra la rabia, la de origen humano que es bien más cara y utilizada en los países ricos y la de origen animal que es la utilizada en varios países, como en Brasil. Los riesgos de intercurrencias con la utilización de suero heterólogo es bastante mayor que con homólogo, pero no se han notificados muchos problemas con la utilización de este producto en Brasil, dónde son tratadas anualmente cerca de 18.000 personas con suero + vacuna ${ }^{34}$.

Al recordar los modelos para explicar la ocurrencia de las enfermedades, el modelo biologista que inició con los descubrimientos microbianos de Pasteur, Koch y otros, continuó siendo hegemónico hasta los años 60 , cuando empezaron a surgir otras teorías, como el modelo ecológico de Leawell et al. ${ }^{21,22}$ teoría de la multicasualidad, propuesta inicialmente por MacMahon. Este último autor establece el concepto de red de causalidad, sugiriendo que es más importante saber dónde intervenir para el control de una enfermedad que conocer su causa. El tratamiento humano en personas expuestas, evitando así la enfermedad, así como la vacunación de perros que disminuye la transmisión, son dos formas de intervenir en la cadena; ambas acciones muy utilizadas por los programas oficiales de control de la rabia.

Estas acciones desde nuestro punto de vista están correctas, aunque muchas veces no son realizadas de la manera adecuada; no obstante, nuestra preocupación es de no quedarse solamente en ellas, sin preocuparse por qué todavía hay rabia en algunos lugares y en otros no.

El modelo de la determinación histórico social del proceso salud enfermedad ${ }^{6,20}$ que surgió en los años 70, después de pasar 150 años sin hablar sobre el aspecto social en la enfermedad, como las teorías revolucionarios de Virchow y otros médicos del final del siglo XVIII, viene contribuyendo para comprender los procesos que 
envuelven la ocurrencia de la rabia en los días de hoy. ¿Por qué todavía hay rabia en personas en países pobres y no más en países ricos? Así mismo, el surgimiento de algunos brotes de rabia humana por murciélagos en determinados tipos de procesos productivos ${ }^{35}$ pudieran ser analizados con base a este modelo.

En la mayoría de los países, las Normas Técnicas de Tratamiento Antirrábico son iguales en todo el territorio, no tomando en consideración a las diferentes situaciones epidemiológicas y al desarrollo de acciones de control de la rabia que llevan a distintos niveles de riesgo ${ }^{12,34}$. Con base en las diferentes situaciones epidemiológicas el Ministerio de Salud de Brasil elaboró dos tipos de Normas para el tratamiento a personas agredidas, dependiendo del riesgo de rabia en el municipio ${ }^{13}$; dónde se considerado como de bajo riesgo, se observa al animal en lugar de tratar a la persona con agresiones graves. Además, se estableció una recomendación específica para situaciones de riesgo para la rabia humana transmitida por murciélagos $^{35}$, en la cual es recomendado el tratamiento pre-exposición.

Los diferentes esquemas recomendados y los diferentes tipos de vacunas existentes son la situación actual con relación al tratamiento antirrábico humano.

\section{Conclusión}

Los conocimientos sobre la historia natural de la rabia y de su forma de transmisión poco cambió en 2.000 anos. Su cadena básica de transmisión era conocida desde tiempo inmemorables, tanto que permitió desde la antigüedad utilizar formas de tratamiento para evitar la penetración del virus; como el ejemplo de la cauterización, que fue utilizada hasta el descubrimiento de la vacuna Pasteur. Es claro que se conoció mucho más sobre la enfermedad cuando se identificó el virus y se desarrollaron estudios en varios campos, incluso sobre diagnóstico, pero la esencia casi no cambió.

Algo semejante pasó con el tratamiento, después del descubrimiento de la vacuna de Pasteur muchas otras vacunas más eficaces y con menores riesgos surgieron, pero la concepción básica del tratamiento persiste. Sigue siendo aplicado un inmunógeno, en la tentativa de obtener una respuesta inmune al virus de la rabia en la persona expuesta al riesgo de contraer rabia. El tipo de vacuna ha sido mejorado, el número de dosis disminuyó, fué adicionado el suero al tratamiento, pero el paradigma es el mismo.

Creemos que las investigaciones en térmi- nos de tratamiento contra la rabia actualmente son más con el objetivo comercial de desarrollar una vacuna comercialmente más vendible, que en hacer grandes cambios en la forma de tratar a la rabia. Es claro que existen muchos estudios actualmente enfocados a la producción de la mejor vacuna y el mejor esquema profiláctico, pero el problema en términos técnicos ya está resuelto. En nuestro punto de vista el problema fue resuelto por Pasteur, desde entonces apenas el tratamiento viene siendo perfeccionado.

La condición técnica de controlar la rabia, dado por Pasteur viene siendo muy bien utilizada por muchos países, principalmente los ricos. Inglaterra y Japón han logrado erradicar la enfermedad. Otros países, como Estados Unidos y Alemania, tienen solamente problemas con el ciclo silvestre, manteniendo la enfermedad en personas y animales domésticos bajo control. Por otro lado, en la India todavía ocurren cerca de 25.000 defunciones humanas por rabia anualmente ${ }^{46}$. El gran brinco con relación a la rabia desde Pasteur hasta hoy no ha sido más en términos de innovaciones terapéuticas, pero sin en la situación epidemiológica de la enfermedad.

En la mayoría de los países de Latinoamérica la rabia es un serio problema de salud pública hasta hoy, causando muchas muertes que pudieran ser evitadas. Los países que más notifican casos humanos en números absolutos son México y Brasil con 69 y 73 defunciones, respectivamente en $1990^{26}$. Pero otros países como El Salvador, Ecuador y Peru presentan tasas de mortalidad mucho más altas. Está probado que el control del ciclo urbano de la rabia no es más un problema científico, ni técnico, más sí una decisión política de hacerlo.

\section{Agradecimientos}

Al Dr. George M. Baer, que revisó este trabajo, además de permitir la consulta a su biblioteca personal contribuyendo en mucho la realización de esta revisión. A la Dra. Esther Chamelet, pela colaboración técnica. $\mathrm{Al} \mathrm{CNPq}$ de Brasil que costea la beca doctoral de Maria Cristina Schneider.

SCHNEIDER, M.C. \& SANTOS-BURGOA, C. Tratamento contra a raiva humana: um pouco de sua histária. Rev. Saúde Pública, 28: 454-62, 1994. Trata-se de uma revisão histórica sobre o tratamento utilizado contra a raiva, desde a antigüidade até o momento atual. Pretendese fazer uma analogia entre o conceito de causa predominante na época, com o tipo de tratamento preconizado. Os gregos antigos tinham a deusa Artemisa como sanadora da raiva e já utilizavam a cauterização da 
ferida. Os povos do século I conheciam a infecciosidade na saliva de cães raivosos, chamando esse material de veneno ("virus" en latin). Na Idade Média, com um conceito mágico e religioso da saúde, o grande protetor era São Humberto. Com o renascimento surgem novamente muitos experimentos e avanços no conhecimento da doença, que deram as bases para importantes achados. Nessa época predominava a teoria miasmática e de contágio. Pasteur foi um grande opositor da espontaneidade da raiva. No final do século XIX, com os descobrimentos microbianos, Pasteur realizou a grande revolução científica em relação ao tratamento contra a raiva, que é a vacina. Essa atualmente pode ser de tipo nervoso ou não, variando também o número de doses recomendadas. Desenvolveram-se muitos estudos sobre vacinas, entretanto a mais utilizada na América Latina é a de tipo Fuenzalida e Palacios e a recomendada atualmente pela OMS é a de cultivo celular.

Descritores: Raiva, prevenção \& controle. Vacina antirábica.

SCHNEIDER, M.C. \& SANTOS-BURGOA, C. [A historical review of the treatment of human rabies]. Rev. Saúde Pública, 28: 454-63 1994. A historical review of the treatment of human rabies from ancient times up to the present is undertaken. An attempt is made to trace parallel between the concept of the main cause of rabies in a certain period and the kind of treatment utilized. The ancient Greek goddess Artemis was considered to be a healer of rabies; they already identified wound cauterization. People of the first century A.D. knew of the infection deriving from the saliva of a rabid dog and called it virus (in Latin). During medieval times when a magical and religious concept regarding health was prevalent, the principal protector was called St. Humbert. During the Renaissance many experiments were carried out and new information on the disease was obtained, both were basic in opening the way for new findings in the future. At that time the miasmatic and contagious theories were predominant. Pasteur strongly objected to the idea of the spontaneity of rabies. At the end of the XIXth. century and based on microbial discoveries, Pasteur brought about a great scientific revolution as regards the possibility of treating rabies by using a vaccine. At the present time, vaccines are of the nervous type or not, and the recommended dose varies. A large-number of studies on vaccination have been undertaken. In Latin America the most used are those by Fuenzalida and Palacios. At present, WHO recommends the vaccine made by cell culture.

Keywords: Rabies, prevention \& control. Rabies vaccine.

\section{Referencias Bibliográficas}

1. BAER, G.M. História natural de la rabia. Mexico, Ed. La Prensa Médica Mexicana, 1975.

2. BAER, G. Estado actual de la vacuna antirrábica en América Latina. In: Reunión de Consulta sobre la atención a pensonas expuestas a la rabia transmitida por vampiros. Washington, OPS 1991.
3. BALTAZAR, M. \& GHOPSSI, M. Prevention of human rabies. Bull. World Health Organ., 10-797-803. 1954.

4. BARATA, R.C. B. A historicidade do conceito de causa. In: Barata, R. C. B. et al. Textos de apoio: epidemiologia 1. Rio de Janeiro, ENSP/ABRASCO, 1985. p. 13-27.

5. BERLIN, B. et al. Rhesus diploid rabies vaccine (adsorbed), a new rabies vaccine. J. Am. Med. Assoc., 247: 1726-8, 1982

6. BREILH, J. Epidemiologia: economía, medicina e política. Quito, Ed. U. Central, 1979.

7. BUNGE, M. Casualidad: el principio de casualidad en la ciencia moderna. $3^{\mathrm{a}}$ ed. Buenos Aires, Ed. Universidade de Buenos Aires, 1972.

8. CABASSO, V. J. Imunización pasiva. In: Baer, G.M. Historia natural de la rabia. México, La Prensa Médica Mexicana, 1975. p 361-8.

9. ClARK, H. F. et al. Vacunación humana contra la rabia. In: Baer, G. M. Historia natural de la rabia. México, La Prensa Médica Mexicana, 1975. p. 339-64.

10. CRICK, J. Rabies since Pasteur. Vet. Rec, 27, 1985.

11. DIAZ. A.M. et al. Vacuna antirrábica de cerebro de ratón lactante, esquemas reducidos de inmmunización. Rev. Argent. Microbiol., 11:42-4,1979.

12. FUNDACÃO NACIONAL DE SAÚDE. Normas técnicas por profilaxia de raiva human em áreas de risco de agressão por morcego. Brasilia, Fundação Nacional de Saúde, 1991

13. FUNDAÇĀO SESP. Norma técnica de tratamento preventivo contra a raiva humana. Rio de Janeiro, Fundação SESP, 1987.

14. GREENBERG, M. \& CHILDRESS, J. Vaccination against rabies eith duckembryo and semple vaccines. $J$. Am. Med. Assoc., 173: 333-7, 1960,

15. KITALA, P.M. et. al. Comparison of human immune responses to purified vero cell and human diploid cell rabies vaccines by using two different antibody titration methods. J. Clin. Microbiol., 28:1847-50,1990.

16. KOPROWSKl, $\mathrm{H}$. et al. Use of hyperimmune antirabies serum concentrates in experimental rabies. Am. J. Epidemiol., 8: 412-20,1950.

17. KOPROWSKI, H. \& COX, H.R. Recent developments in the prophylaxis of rabies. Am. J. Public Health, 41:1483-9, 1985.

18. KUHN, T.S. La estructura de las revoluciones científicas. $8^{\mathrm{a}}$ ed. México, Fondo de Cultura Económica, 1986.

19. KUWERT, E.K. et al. Immunization against rabies with rabies immune globulin, human (RIGH) and human diploid cell strain (HDCS) rabies vaccine. J. Biol. Stand, 6:211-9, 1978.

20. LAURELL, A.C. La salud-enfermedad como proceso social. Rev. Latinoam. Salud, 1(2):7-25, 1081

21.LEAWELL, H.R. \& CLARK, E.G. Preventive medicine for the doctor in the community an epidemiologic approach. New York, MacGraw-Hill, 1965.

22. MACMAHON, B. \& PUGH, T. Epidemiology: principles and methods. Boston, Little, Brown and Company, 1970.

23. MARWICK, C. Changes recommended in use of human diploid cell rabies vaccine. J. Am. Med. Assoc., 254:134, 1985.

24. NELSON, $K$. et al. Purified durk embryo rabies vaccine. $J$. Am. Med. Assoc., 237:218-20, 1977.

25. OMS. COMITÉ DE EXPERTOS DE LA OMS SOBRE RABIA, Ginebra, 1983.7'Informe. Ginebra, Organización Mundial de la Salud, 1984. (OMS - Serie de Informes Técnicos, 709).

26. ORGANIZAÇĀO PANAMERICANA DE LA SALUD. Vigilancia epidemiológica de la rabia en las Américas, 1990. Washington, (-12). 1991.

27. PARA, M. et al. Raiva de laboratório: accidente pós-vacinal ocurrido em Fortaleza - Ceará, Brasil, 1960. Bol. Oficina 
Sanit. Panam., 56:550-9,1964.

28. PASTEUR. L. Oeuvres de Pasteur. Padris, Masson, 1933. v.6: Maladies virulentes, virus vaccins et prophylatre de la rage.

29. RADOT, R.V. La vida de Pasteur. $3^{2}$ ed. Buenos Aires, Juventud Argentina, 1942.

30. ROSANOFF, E. \& TINT, H. Responses to human diploid cell rabies vaccine: neutralizing antibody responses of vaccines receiving booster doses of human diploed cell rabies vaccine. Am. J. Epidemiol., 110:322-7,1977.

31. ROSEN, G. A. History of public health. New York, MD Publications, 1958.

32. RUEGSEGGER, J. \& SHARPLESS, G. Flury rabies vaccine for human use. Inter. Med., 110:754-7, 1962.

33. SCHELERMANN, N. et al. Reactigenicity and immunogenicity of the newly developed purified chick embryo cell (PCEC) Rabies vaccine in man. ZbL Bakt. Hyg., A265:439-50, 1987.

34. SCHNEIDER, M.C. Estudo de ava liação sobre área de risco para a raiva no Brasil. Rio de Janeiro, 1990. [Dissertação de Mestrado - Escola Nacional de Saúde PúblicaFIOCRUZ].

35. SCHNEIDER, M.C. Situación epidemiológica de la rabia transmitida por murciélagos en Brasil: el brote de Apiacaí/ MT.In: Reunión de Consulta sobre la atención a personas expuestas a la rabia transmitida por vampiros. Anais. Washington, Ed. OPS, 1991.

36. SHARPLESS, G. et al. Preliminary observations in primary antirabies immunization of man with different types of high-egg-passage flury virus. Bull. World Health Organ., 17:905-10,1957.

37. SIKES, K. R. \& LARGHI, O. P. Purified rabies vaccine: development and comparison of potency and safety with two human rabies vaccines. J. Immunol., 99:545-53, 1967.
38. SIKES, R. Rabies vaccines. Arch. Environ. Health., 19: $862-$ $7,1969$.

39. STEELE, J.H. History of rabies. In: Baer, G.M. The natural history of rabies. New York, Academic Press, 1975. p. 129.

40. SUNTHARASAMAI, P. et al. Purified vero cell rabies vaccine and human diploid cell strain vaccine: comparison of neutralization antibody responses to postexposure regimens. J. Hyg., 96:483-9, 1986.

41. SUSSER, M. Causal thinking in the health sciences concepts and strategies of epidemiology. New York, Oxford University Press, 1973.

42. THEORODIDES, J. Historie do la rage. Paris, Foudation Singer-Polignan, 1986.

43. TURNER, G.S. Rabies vaccines. Br. Med. Bull., 25:136$42,1969$.

44. TURNER, G.S. Rabies prophylaxis. Hosp. up Date, July, 679-87, 1981

45. TURNER, G.S. et al. Evaluation of a human diploid cell strain rabies vaccine: final report of a three year study of pre-exposure immunization.J. Hyg. Camb., 89:101-10, 1982.

46. WORLD HEALTH ORGANIZATION. World survey of rabies, years 1984-85. Geneva, 1986. (WHO-Rabies 187,198).

47. WHOEXPERT COMMITTEE ON RABIES, Geneva, 1991. 8th Report. Geneva, World Health Organization, 1992. (WHO - Technical Report Series, 824).

Recebido para publicación en 14.3.1994 Aprobado para publicación en 18.10.1994 